\title{
RDUS
}

Revue de DROIT

UNIVERSITÉ DE SHERBROOKE

Titre : $\quad$ LES FRONTIÈRES TERRESTRES D'UN QUÉBEC SOUVERAIN À LA LUMIÈRE DU DROIT INTERNATIONAL CONTEMPORAIN

Auteur(s) : $\quad$ Tara LEROUX

Revue : $\quad$ RDUS, 1994-1995, volume 25, numéro 1-2

Pages: $\quad 239-284$

ISSN : $\quad 0317-9656$

Éditeur : $\quad$ Université de Sherbrooke. Faculté de droit.

URI : $\quad$ http://hdl.handle.net/11143/12914

DOI : $\quad$ https://doi.org/10.17118/11143/12914 
Page vide laissée intentionnellement. 


\title{
ARTICLE
}

\section{LES FRONTIÈRES TERRESTRES D'UN QUÉBEC SOUVERAIN À LA LUMIĖRE DU DROIT INTERNATIONAL CONTEMPORAIN}

\author{
par Tara LEROUX
}

L'accession à la souveraineté d'États issus des récentes dissolutions de l'Union soviétique, de la Yougoslavie et de la Tchécoslovaquie, a permis de créer, de renforcer ou de mitiger certains principes de droit international quant à la détermination des frontières d'un nouvel État.

En vertu de la Convention de Vienne sur le droit des traités et de la Convention de Vienne sur la succession d'États en matière de traités, un Québec souverain conserverait, à moins d'accord contraire, son unique frontière internationale qui le borde actuellement comme État fédéré. Quant à l'uti possidetis juris, règle juridique protégeant les limites intérieures des États destinées à devenir des frontières, elle permet l'attribution à un Québec souverain des frontières délimitant son territoire provincial. Cette thèse n'est valable qu'en l'absence de tout exercice du droit de sécession ou de rattachement au Canada par les peuples autochtones. Face à un tel exercice de leur droit à l'autodétermination, le Québec se verrait amputer des régions territoriales alors sous leur contrôle effectif.

1. LL.B., Faculté de droit de l'Université de Montréal. 
The creation of independant States as a result of the break-up of the Soviet Union, Yugoslavia and Czechoslovakia has fostered the elaboration, the reaffirmation and the modification of certain principles of International Law with respect to the determination of the frontiers of a new State.

Pursuant to the Vienna Convention on the law of treaties and to the Vienna Convention on succession of States in respect to treaties, a sovereign Quebec, barring any agreement to the contrary, would retain its present frontiers. As for the principle of uti possidetis juris, a rule of law which preserves the internal State boundaries which are then destined to become national frontiers, it would permit an independant Quebec to claim that its frontiers extend to the boundaries presently defining its provincial territory. This argument would only hold provided that the First Nations declined to exercise their right of secession or their right to rejoin Canada. If such a right to self-determination were to be exercised, then those territories effectively under aboriginal control would be severed from a sovereign Quebec. 


\section{SOMMAIRE}

Chapitre I L'accession à la souveraineté du Québec et le maintien des frontières établies par traités . . . . . . . . . . 248

1.1 La formulation et la consolidation de la règle du maintien des frontières établies par traités . . . . . . . . . . . . 248

1.1.1 La formulation de la règle dans la Convention de Vienne sur le droit des traités . . . . . . . . . . . . . 248

1.1.2 La consolidation de la règle dans la Convention de Vienne sur la succession d'États en matière de traités ......................... 249

1.2 L'application de la règle du maintien des frontières établies par traités avec les États-Unis . . . . . . . . . . . . . . 252

1.2.1 L'obligation du maintien des frontières établies par les traités de Paris (1782), Ashburton-Webster (1842) et de Washington (1908) ................ 253

1.2.2 L'opportunité d'un réajustement des frontières avec les

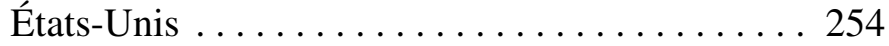

Chapitre II L'accession à la souveraineté du Québec et l'intangibilité des frontières protégées par l'uti possidetis juris . . . . . 255

2.1 L'universalité et le renforcement de la règle de l'uti possidetis ............................ 255

2.1.1 L'universalité de la règle de l'uti possidetis . . . . 256

2.1.2 Le renforcement de la règle de l'uti possidetis . . 260

2.2 L'application de la règle de l'uti possidetis aux frontières intérieures du Québec .................. 261

2.2.1 L'intangibilité des frontières intérieures actuelles du

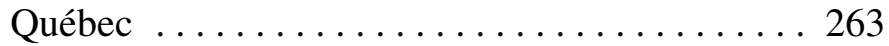

2.2.2 La protection de l'intégrité du territoire intérieur du

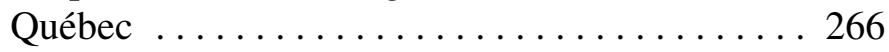

Chapitre III L'accession du Québec à la souveraineté et le problème de l'intégrité du territoire québécois en cas de revendications

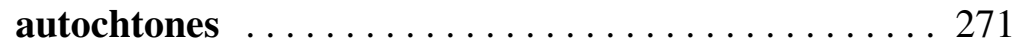

3.1 Les nations autochtones : des peuples minoritaires . . . 272 
3.2 Contestation de l'application de la règle de l'uti possidetis au Québec .......................... 277

3.3 Le territoire des nations autochtones : territoire sur lequel ils ont

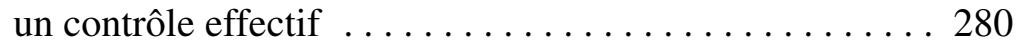


À l'heure où les référendums et les déclarations de souveraineté se multiplient à travers le monde, consacrant démocratiquement la volonté des peuples d'accéder à l'indépendance, la carte du monde ne cesse de se redessiner en fonction des nouvelles aspirations des peuples.

Victime de ces bouleversements, la République socialiste fédérative de Yougoslavie a éclaté dès juin 1991 sous la pression des revendications de la Croatie, de la Slovénie, de la Macédoine en septembre 1991 et de la BosnieHerzegovine en mars 1992. La Serbie et le Monténégro ayant formé la «République fédérale de Yougoslavie», cinq nouveaux États se sont ainsi constitués sur les cendres de l'ex-Yougoslavie. Quant à l'ancienne Union soviétique, sa dissolution s'est amorcée avec les déclarations d'indépendance des États Baltes, celle de la Lituanie le 11 mars 1990, de l'Estonie le 20 août 1991 et de la Lettonie le 21 août 1991. Mais c'est véritablement la proclamation d'indépendance de l'Ukraine, le 24 août 1991, qui a mis fin à l'Union soviétique, car elle fut le prélude aux déclarations d'indépendance des autres républiques soviétiques. Ces dernières étant parfois elles-mêmes victimes de revendications internes sécessionnistes comme le démontre l'exemple de la Géorgie indépendante qui a du faire face à la sécession de facto de la République autonome d'Abkhazie à l'hiver 1993-1994. Même si la fédération de Russie s'est avérée l'héritière de l'U.R.S.S., elle n'en demeure pas moins affectée par les revendications sécessionnistes de certaines de ces républiques, comme l'a démontré l'indépendance de la Tchétchénie ${ }^{1}$ en 1991, ainsi que la proclamation d'indépendance du Tatarstan en mars $1992^{2}$. Enfin, la fédération de la Tchécoslovaquie s'est dissoute pacifiquement grâce au «divorce de velours» entre les Tchèques et les Slovaques le 1er janvier 1993, une séparation pacifique qui pourrait s'avérer une source d'inspiration pour certains promoteurs d'une partition analogue d'une Belgique, devenue récemment fédérale ${ }^{3}$.

Ces bouleversements qui affectent principalement les États fédératifs, tant anciens que nouveaux, ne sauraient laisser indifférents les Québécois

1. Le 11 décembre 1994, les troupes russes ont envahi la République tchétchène et réussirent, le 8 février 1995, à contrôler la quasi-totalité du territoire.

2. L'État du monde 1995 : Annuaire économique et géopolitique mondial, Montréal, Éditions la Découverte, 1994.

3. REUTER, «La Belgique transformée en État fédéral», Le Devoir, 8 février 1993, pp. A1-A8. 
soucieux de l'avenir du Québec et notamment de l'espace sur lequel un Québec souverain serait appelé à déployer son autorité. Aussi, est-il intéressant de s'interroger sur les répercussions locales de tels bouleversements et de se demander s'ils peuvent tout particulièrement avoir un impact sur les revendications de souveraineté des Québécois et sur l'expression territoriale de leurs revendications.

Même si le gouvernement du Parti Québécois se voyait refuser le 20 mai 1980 le mandat de négocier la souveraineté-association avec le Canada, les velléités souverainistes des Québécois sont réapparues au lendemain du rapatriement et de la modification de la Constitution du Canada sans l'assentiment du Québec en 1982. Ces revendications se sont multipliées depuis la mort de l'Accord du lac Meech et ont été confortées par le refus en 1992, tant par le Québec que par le reste du Canada, mais pour des raisons diamétralement opposées, d'approuver un Accord de Charlottetown visant à satisfaire la demande d'un nouveau partenariat constitutionnel souhaité par le gouvernement du Parti libéral du Québec.

L'accession du Québec à la souveraineté qui avait été envisagée par la Commission Bélanger-Campeau dans le cas où il aurait été impossible de renouveler le fédéralisme canadien en profondeur, se révèle aujourd'hui une option possible depuis les élections du Bloc Québécois le 25 octobre 1993 et du Parti Québécois le 12 septembre 1994.

L'accession à la souveraineté du Québec trouvera son fondement principal dans une légitimité démocratique qui résulte non seulement d'une élection, mais également d'un référendum québécois. Il n'est, cependant, pas sans intérêt de se pencher sur le fondement juridique de la revendication du peuple québécois d'un droit de se constituer en État. Ce droit a, selon nous, sa source dans le droit des peuples à disposer d'eux-mêmes, garanti dans de nombreux traités ${ }^{4}$, et notamment dans les Pactes internationaux relatifs aux

4. J. BROSSARD, L'accession à la souveraineté et le cas du Québec, Montréal, P.U.M., 1976; D. TURP, «Le droit de sécession en droit international public», (1982) 20 A.C.D.I. 25-78. 
droits de l'Homme, auxquels le Canada est d'ailleurs partie ${ }^{5}$, et dont l'article 1 qui leur est commun se lit ainsi :

«Tous les peuples ont le droit de disposer d'eux-mêmes. En vertu de ce droit, ils déterminent librement leur statut politique et assurent librement leur développement économique, social et culturel.»

En dépit de l'absence de définition du terme «peuple», le droit des peuples à disposer d'eux-mêmes revêt selon nous un caractère universel. Ainsi, tous les peuples, et non pas seulement les peuples coloniaux comme le prétendent certains, ont le droit de disposer d'eux-mêmes et de déterminer librement leur statut politique en se constituant en États souverains. Nous sommes par ailleurs d'avis que la résolution 2625 de l'Assemblée générale des Nations Unies $^{6}$, qui a cherché à délimiter la portée du droit des peuples à disposer d'eux-mêmes et à restreindre, au nom du principe de l'intégrité territoriale et de l'indépendance politique des États, le droit des peuples non coloniaux à se constituer en États souverains, ne constitue pas un obstacle au droit pour un peuple de se constituer en État. Cette déclaration ne revêt pas un caractère obligatoire en soi. Elle ne codifiait pas en 1970 une règle coutumière et n'a certainement pas été suivie depuis. Faute d'une pratique uniforme et constante tendant à prohiber l'accession d'un peuple non-colonial à la souveraineté, comme le démontre la pratique récente en Yougoslavie, en Union soviétique et en Tchécoslovaquie, la résolution 2625 de l'Assemblée générale n'a pas servi de base, en ce domaine, à l'élaboration d'une règle coutumière.

En ce qui concerne le cas particulier du droit à l'autodétermination du Québec, nous constatons par ailleurs l'existence d'une convention constitutionnelle canadienne consacrant le droit du Québec de se constituer en État

5. Pacte international relatif aux droits civils et politiques, (1976) 999 R.T.N.U. 107. Pacte international relatif aux droits économiques, sociaux et culturels, (1976) 993 R.T.N.U. 13.

6. Déclaration relative aux principes de droit international touchant les relations amicales et la coopération entre les États conformément à la Charte des Nations Unies, A.G. Rés. 2625, Doc. off. A.G., 25e session, supp. n 28, p. 131, Doc. N.U. A/5217 (1970) (ci-après dénommée Déclaration sur les relations amicales). 
souverain ${ }^{7}$. Appliquant les critères énoncés par la Cour suprême du Canada, nous constatons la création de précédents tels que la tenue d'un référendum sur la souveraineté-association en 1980 et l'adoption d'une loi prévoyant la tenue d'un référendum sur la souveraineté en 1991, la reconnaissance par les acteurs politiques québécois et par les acteurs fédéraux et provinciaux du reste du Canada du droit pour le peuple québécois à disposer de lui-même, et enfin, l'existence d'une raison d'être à la convention qui résiderait dans le principe démocratique, ou selon un autre auteur dans «la dualité canadienne ou le caractère distinct du Québec $»^{8}$.

Que l'accession à la souveraineté du Québec trouve son fondement dans une légitimité démocratique conséquente à une élection et à un référendum, dans le droit à l'autodétermination du peuple québécois, ou dans une convention constitutionnelle, elle s'avérera à tout le moins une question de fait au regard du droit international ${ }^{9}$. À cet égard, l'opinion collective sollicitée par la Commission d'étude des questions afférentes à l'accession du Québec à la souveraineté reprend à son compte l'avis de la Commission d'arbitrage de la Conférence de paix en Yougoslavie ${ }^{10}$ :

«L'existence ou la disparition de l'État est une question de fait qui doit être appréciée en fonction des principes du droit international public qui permettent de définir à quelles conditions une entité constitue un État; pour cela il convient de déterminer si la collectivité en cause se

7. D. TURP, «Exposé-réponse : processus d'accession à la souveraineté», reproduit dans Recueil des exposés et études soumis à la Commission d'étude des questions afférentes à l'accession du Québec à la souveraineté, volume 1, tome 2, 1992, p. 662.

8. Voir à ce sujet C. BEAUCHAMP, «De l'existence d'une convention constitutionnelle reconnaissant le droit du Québec à l'autodétermination», (1992) 6 R.J.E.U.L. 55-67; voir aussi D. TURP, loc. cit., supra, note 7.

9. T.M. FRANCK, R. HIGGINS, A. PELLET, M. N. SHAW et C. TOMUSCHAT, «L'intégrité territoriale du Québec dans l'hypothèse de l'accession à la souveraineté», reproduit dans Recueil des exposés et études soumis à la Commission d'étude des questions afférentes à l'accession du Québec à la souveraineté, volume 1, tome 2, 1992, p. 409 (ci-après dénommé T.M. FRANK).

10. Avis de la Commission d'arbitrage pour la Yougoslavie, reproduit dans (1992) 96 R.G.D.I.P. 264-266. 
compose d'un territoire et d'une population soumis à un pouvoir politique organisé et si elle se caractérise par la souveraineté.» ${ }^{11}$

Cette question de fait sera essentiellement celle de l'effectivité du contrôle exercé par le gouvernement québécois sur sa population et son territoire et elle s'appréciera eu égard aux particularités de celui-ci, tels l'aspect physique du territoire, la situation géographique, l'accessibilité, le climat et la densité de la population ${ }^{12}$. Encore faut-il définir l'assiette territoriale sur laquelle ce contrôle effectif pourrait se déployer et déterminer ainsi l'étendue et les frontières du territoire d'un Québec souverain ${ }^{13}$. Le droit international fournit quelques repères utiles sur la question des frontières qui seraient celles d'un état accédant à la souveraineté.

Pour procéder à un examen des frontières terrestres d'un éventuel Québec souverain, nous présenterons dans un premier temps les principes et instruments juridiques applicables à la succession d'un nouvel État aux frontières internationales préexistantes établies par traités (Chapitre I) et nous nous interrogerons dans un deuxième temps sur le sort qui devrait être réservé aux frontières intérieures actuelles du Québec (Chapitre II). Nous terminerons en examinant les conséquences d'éventuelles revendications territoriales autochtones sur l'intégrité du territoire québécois (Chapitre III).

11. T.M. FRANCK, loc. cit., supra, note 9.

12. Affaire de l'île de Palmas (États-Unis c. Pays-Bas), sentence du 4 avril 1928, (1928) 2 R.S.A. 829. J.Y. MORIN et J. WOEHRLING, Demain, le Québec ... Choix politiques et constitutionnels d'un pays en devenir, Sillery, les Éditions du Septentrion, 1994.

13. La détermination du territoire et des frontières maritimes d'un Québec souverain s'avère une question importante et a suscité l'intérêt de la Commission d'étude sur la souveraineté. J. I. CHARNEY, «The Maritime Boundaries of Québec», reproduit dans Recueil des exposés et études soumis à la Commission d'étude des questions afférentes à l'accession du Québec à la souveraineté, volume 1, tome 2, 1992, pp. 493-577; M. ARBOUR, «Les territoires aquatiques et maritimes», dans Les frontières du Québec : d'hier à demain, Québec, Faculté de foresterie et de géomatique de Laval, 1992, p. 41. 


\section{Chapitre I L'accession à la souveraineté du Québec et le maintien des frontières établies par traités}

\subsection{La formulation et la consolidation de la règle du maintien des frontières établies par traités}

\subsubsection{La formulation de la règle dans la Convention de Vienne sur le droit des traités}

La Convention de Vienne sur le droit des traités ${ }^{14}$, qui codifie le droit coutumier en cette matière, insiste particulièrement sur l'importance de maintenir la stabilité des traités établissant des frontières. Cette insistance se traduit par l'adoption d'une exception à la règle rebus sic stantibus, codifiée au paragraphe 2 de l'article 62 et selon laquelle :

«§ 2- Un changement fondamental de circonstances ne peut pas être invoqué comme motif pour mettre fin à un traité ou pour s'en retirer:

a) s'il s'agit d'un traité établissant une frontière;» (l'italique est de nous)

En raison des conséquences importantes qu'elle engendre aux plans économique, social, culturel et politique, l'accession à la souveraineté constitue sans nul doute un «changement fondamental de circonstances». L'accession à la souveraineté est en outre un changement fondamental de circonstances qui pourrait conduire à une remise en question des frontières établies par traités, mais l'exception prévue à l'application de la règle rebus sic stantibus vient justement prohiber l'invocation de cette règle à l'égard des traités établissant des frontières. L'existence d'une telle règle vient affirmer la volonté de nombreux États de stabiliser les situations territoriales ${ }^{15}$, une volonté qui est rappelée dans la Convention de Vienne sur la succession d'États en matière de traités.

14. [1980] R.T. Can. $n^{\circ} 37$.

15. Voir J. COMBACAU et S. SUR, Droit international public, Paris, Montchrestien, 1993, p. 146. 
Les frontières terrestres

(1994-95) 25 R.D.U.S. d'un Québec souverain à la lumière

\subsubsection{La consolidation de la règle dans la Convention de Vienne sur la succession d'États en matière de traités}

Ce principe du maintien des frontières établies par traités est d'ailleurs consolidé dans la Convention de Vienne sur la succession d'États en matière de traités ${ }^{16}$. Définie à l'alinéa 2(b) de la Convention, la succession d'États se dit de «la substitution d'un État à un autre dans la responsabilité des relations internationales d'un territoire», et implique ainsi un transfert de souveraineté sur la totalité ou une partie du territoire, de l'État prédécesseur à l'État successeur. Une telle succession d'États est susceptible de produire des effets à l'égard des traités et la Convention formule plusieurs règles à cette fin. Concernant les traités de frontières, la Convention stipule à son article 11 :

«Une succession d'États ne porte pas atteinte en tant que telle :

a) à une frontière établie par un traité; ni

b) aux obligations et droits établis par un traité et se rapportant au régime d'une frontière.» (l'italique est de nous)

Pour les juridictions internationales, cette règle est renforcée par le principe de l'uti possidetis juris ${ }^{17}$ et est considérée par des auteurs comme codifiant une règle coutumière $^{18}$. Elle semble par ailleurs être reflétée dans la

16. Doc. N.U. A/CONF. 80/16/Add. 2 et reproduite dans J.-Y. MORIN, F. RIGALDIES et D. TURP, Droit international public : notes et documents, Montréal, Les Éditions Thémis Inc., 2e éd., 1990, p. 253. Cette convention a été adoptée le 23 août 1978, mais n'est pas encore en vigueur au 31 décembre 1993. Cette définition se retrouve également à l'article 2 de la Convention de Vienne sur la succession d'États en matière de biens, archives et dettes d'États. Elle est reprise par la Commission d'arbitrage pour la Yougoslavie dans son avis $\mathrm{n}^{\circ} 1$, supra, note 10 .

17. Ce principe est défini dans : Affaire du différend frontalier (Burkina Faso c. République du Mali), arrêt du 22 Décembre 1986, C.I.J., Recueil 1986, p. 554, n 19-26; Différend frontalier terrestre, insulaire et maritime (El Salvador c. Honduras; Nicaragua (intervenant)), arrêt du 11 septembre 1992, Arrêt C.I.J. Recueil 1992, p. 351; voir aussi Affaire de la délimitation de la frontière maritime entre la Guinée et la Guinée Bissau, sentence du 14 février 1985, (1990) 9 R.S.A. 149.

18. D. TURP, «Intangibilité des frontières terrestres du Québec et succession d'États en droit international», dans Les frontières du Québec : d'hier à demain, Québec, Faculté de foresterie et de géomatique de l'Université Laval, 1992, p. 77; voir aussi D. TURP et F. 
pratique contemporaine. Ainsi, la Slovénie ${ }^{19}$ a maintenu ses frontières avec l'Autriche, l'Italie et la Hongrie. La Croatie ${ }^{20}$ demeure bordée par la Hongrie et la mer Adriatique. La Macédoine continue d'être encadrée par l'Albanie, la Grèce et la Bulgarie ${ }^{21}$. Il est également intéressant de noter que la République tchèque et la République slovaque se sont entendues pour essayer de maintenir les mêmes frontières internationales que celles existantes dans l'ancienne Tchécoslovaquie ${ }^{22}$. En effet, la Hongrie, pays frontalier de l'ex-fédération, a pris position pour que soit respecté le principe de l'intangibilité des frontières, en exprimant sa conviction quant à l'importance de conserver les frontières établies par traités. La Hongrie s'est opposée à la construction du barrage

GOUIN, «Étude sur la succession du Québec aux traités auxquels le Canada est partie dans l'hypothèse d'une accession du Québec à la souveraineté», reproduit dans Recueil des exposés et études soumis à la Commission d'étude des questions afférentes à l'accession du Québec à la souveraineté, volume 1, tome 2, 1992, p. 687.

19. Republic of Slovenia Assembly Basic Constitutional Charter (25 juin 1991), reproduit dans (1992) 6 Constitutions of the countries of the world 63, art. 2.

20. Constitutional Decision on the Sovereignty and Independence of the Republic of Croatia, reproduit dans (1992) 6 Constitutions of the countries of the world 123, art. IV.

21. La Commission d'arbitrage pour la Yougoslavie a d'ailleurs recommandé aux républiques dans ses avis $n^{\circ} 3$ ((1992) 96 R.G.D.I.P. 267) et n 9 ((1992) 31 I.L.M. 1523), de suivre la Convention de Vienne sur la succession d'États en matière de traités, afin de respecter les frontières établies par traités.

22. Définies par le traité de Trianon du 4 juin 1920, art. 27, 48 à 52 reproduit dans C.A. COLLIARD, Droit International et histoire diplomatique, 2e éd., Paris, Éditions Domat Montchrestien, 1950, p. 501; Arbitrage de Vienne du 2 novembre 1938 (Texte de la sentence arbitrale) reproduit dans C.A. COLLIARD et A. MANIN, Droit International et histoire diplomatique, Tome II, Paris, Éditions Montchrestien, 1970, p. 140; voir aussi le Traité de paix de Paris. Traité de paix avec la Hongrie (15 Septembre 1947) 61 Stat. 2065 reproduit dans C. I. BEVANS, Treaties and other International agreements of the United States of America 1776-1949, 1946-1949, Washington, Department of State publication, 1970, p. 453; voir aussi le traité bilatéral de 1956; voir également Treaty between the Hungarian people's Republic and the Czechoslovak socialist Republic concerning the construction and operation of the Gabcikovo-Nagymaros system of locks (1977), reproduit dans (1993) 32 I.L.M. 1249, et voir p. 1256 art. 22 et 23 (légers changements de frontières); Declaration of the Government of the Republic of Hungary on the Termination of the Treaty Concluded Between the People's Republic of Hungary and the Socialist Republic of Czechoslovakia on the Construction and joint operation of the Gabcikovo-Nagymaros Barrage System, Signed in Budapest on 16 September 1977 (1992), reproduit dans (1993) 32 I.L.M. 1260 (ci-après dénommé Text of Hungarian Declaration Terminating Treaty); Czech and Slovak Federation-European Commission-Hungary: London Agreement on the Gabcikovo-Nagymaros Project (1992), reproduit dans (1993) 32 I.L.M. 1291. 
hydroélectrique de Nagymaros sur le Danube ${ }^{23}$, car une telle construction aurait, notamment, pour effet de le dévier sur le territoire slovaque, modifiant ainsi de façon arbitraire et unilatérale la frontière ${ }^{24}$.

Par ailleurs, à des fins de sécurité, l'État prédécesseur et l'État successeur peuvent convenir de ratifier les traités établissant les frontières. Le Parlement hongrois a ratifié le 12 mai 1993 un traité sur l'intangibilité des frontières entre la Hongrie et l'Ukraine ${ }^{25}$. La Hongrie a également signé, dernièrement, un traité d'amitié avec la République slovaque, comprenant la reconnaissance des frontières existantes et le renoncement à toutes revendications territoriales. Il faut mentionner qu'«un pacte de stabilité en Europe», non contraignant, a été signé à la fin du mois de mars 1995 à Paris par les 52 pays membres de l'Organisation sur la Sécurité et la Coopération en Europe (O.S.C.E.). Il porte, entre autres, sur l'inviolabilité des frontières des États non touchés par les conflits armés. Ce pacte comprend une centaine d'accords bilatéraux de bon voisinage et d'amitié entre des pays d'Europe, car ce pacte cible l'Europe centrale, orientale et les Républiques baltes. Ce pacte a été signé dans le cadre d'une conférence de l'O.S.C.E. et à l'initiative de l'Union européenne.

Ainsi, à l'occasion d'une succession d'États, un nouvel État doit se montrer soucieux de respecter les frontières établies par traités et les droits et

23. Text of Hungarian Declaration Terminating Treaty, supra, note 22; Czech and Slovak Federation-European Commission-Hungary : London Agreement on the GabcikovoNagymaros Project (1992), supra, note 22; J. URBAN, «Pourquoi le problème tchèque peut déclencher une guerre européenne», L'Événement du jeudi, 29 octobre au 4 novembre 1992, n` 417, p. 68; F. ZDANOWICZ, «La Hongrie tiraillée par son passé», Le Devoir, 25 février 1993, p. B-5; Une demande a été introduite devant la Cour Internationale de Justice, voir Special Agreement Between the Republic of Hungary and the Slovak Republic for Submission to the International Court of Justice of the differences between them concerning the Gabcikovo-Nagymaros Project, reproduit dans (1993) 32 I.L.M. 1294; et voir Projet de Gabcikovo-Nagymaros (Hongrie/Slovaquie): La Hongrie et la Slovaquie portent une affaire devant la Cour, Communiqué C.I.J., 5 juillet et 15 juillet 1993.

24. Le territoire slovaque ne semble pas complètement défini malgré que la frontière délimitant la République tchèque et la République slovaque ait fait l'objet d'un traité signé le 29 octobre 1992, d'un accord de principe conclu en juillet 1993.

25. L'État du monde 1994 : Annuaire économique et géopolitique mondial, Montréal, Éditions la Découverte, 1993, p. 172. 
obligations qui en découlent. Ces règles, visant à assurer la continuité et la stabilité des frontières, ont été développées dans le but de préserver la paix, d'éviter la propagation de conflits territoriaux et de respecter les conventions établies $^{26}$. Le droit de la succession d'États s'attache ainsi davantage au territoire qu'à la qualité de l'État. Ce principe élaborant la stabilité des frontières établies par traités, n'empêche toutefois pas la modification de frontières par accord entre États limitrophes.

Regardons dans quelle mesure cette règle du maintien des frontières établies par traités s'applique à un Québec souverain.

\subsection{L'application de la règle du maintien des frontières établies par traités avec les États-Unis}

Les règles du droit international des traités et celles relatives à la succession d'États en matière de traités revêtent un intérêt particulier pour le Québec, dans la mesure où ces principes obligeraient le Québec souverain, successeur du Canada sur le territoire québécois, à ne pas porter atteinte aux frontières établies par traités. À cet égard, les seules frontières qui seraient visées par cette obligation seraient les frontières terrestres avec les États-Unis puisqu'aucun autre État n'a de frontières terrestres communes avec le Canada.

26. J.- M. ARBOUR, Droit international public, Cowansville, Éditions Yvon Blais, 1985, p. 313 et ss.; H. THIERRY, S. SUR et al., Droit international public, 5e éd., Paris, Éditions Montchrestien, 1986, pp. 269 et ss. 
Les frontières terrestres

(1994-95) 25 R.D.U.S. d'un Québec souverain à la lumière

du droit international contemporain

\subsubsection{L'obligation du maintien des frontières établies par les traités de Paris (1782), Ashburton-Webster (1842) et de Washington (1908)}

Le Canada et les États-Unis ont conclu une vingtaine de traités de frontières, dont certains concernent particulièrement la frontière avec le Québec. La frontière séparant le Québec des États-Unis a été arrêtée d'abord par la Proclamation Royale de 1763, source de l'existence juridique de la province, et par l'Acte de Québec de 1774, ces deux instruments n'étant pas à proprement parler des traités. Mais, quelques années plus tard, le Royaume-Uni et les ÉtatsUnis concluaient un premier traité de frontière, le Traité de Paris de 1783 qui reprenait de façon générale la délimitation frontalière déjà établie pour en préciser la section dite $\ll$ occidentale ${ }^{27}$.

À l'origine d'un conflit qui dura plus de 50 ans, cette section fut révisée par le Traité Ashburton-Webster de $1842^{28}$. La frontière ainsi délimitée et démarquée fut confirmée par le Traité de Washington de $1908^{29}$, conclu entre les États-Unis et le Royaume-Uni au nom du Canada.

Succédant ainsi aux traités établissant la frontière, la frontière d'un Québec souverain continuerait de suivre en général la ligne partageant les eaux entre l'Atlantique et le Saint-Laurent. Un Québec souverain ne pourrait porter atteinte aux frontières qu'ils établissent.

27. H. BRUN, Le territoire du Québec, Québec, P.U.L, 1973, p. 24; H. BRUN et G. TREMBLAY, Droit constitutionnel, 2e éd., Cowansville, Éditions Yvon Blais, 1990, p. 138.

28. A treaty to settle and define the Boundaries between the Territories of the United States and the possessions of Her Britannic Majesty, in North America : For the final Suppression of the African Slave Trade : and For the giving up of Criminals fugitive from justice, in certain cases (Webster-Ashburton Treaty), (1842) 93 The consolidated Treaty Series 415.

29. Treaty between Great Britain and the United States respecting the Demarcation of the International Boundary with Canada, (1907-1908) 206 The Consolidated Treaty Series 377. Treaty between the United Kingdom and the United States desiring to define more accurately at certain points and to complete the international boundary between the United States and Canada and to maintain the demarcation of that boundary (Lake Superior-Lake of the Woods Boundary), (1925) 6 Bevans 7. 
D'ailleurs l'Avant-projet de Loi sur la souveraineté du Québec ${ }^{30}$ reconnaît l'application de ce principe, en affirmant entre autres à son article 4 que «Le Québec conserve les frontières qui sont les siennes au sein de la Confédération canadienne au moment de l'entrée en vigueur de l'article 1», c'est-à-dire lors de l'accession du Québec à la souveraineté. Quant à l'article 7 qui est plus général car il vise l'ensemble des traités et non spécifiquement le territoire, il y est affirmé que le Québec souverain assumera les obligations et bénéficiera des droits contenus dans «les traités auxquels le Canada est partie et dans les conventions internationales auxquelles le Canada a adhéré, conformément aux règles du droit international.»

\subsubsection{L'opportunité d'un réajustement des frontières avec les États-Unis}

Par ailleurs, l'accession du Québec à la souveraineté pourrait être l'occasion pour le Québec et les États-Unis de résoudre, d'un commun accord, le problème frontalier des périclaves. Il s'agit de parties de territoire québécois accessibles uniquement par le territoire des États-Unis et vice-versa. Ce problème mineur pourrait être résolu en suivant les recommandations de la Commission d'étude sur l'intégrité territoriale de $1971^{31}$, c'est-à-dire par un réajustement de la frontière internationale afin de faire disparaître de telles périclaves. En l'absence d'un réajustement de la sorte, le droit de passage actuel serait maintenu en vertu des règles relatives à la succession d'États à l'égard des régimes de frontières ${ }^{32}$.

Si l'on ne doit pas négliger l'importance du maintien par le Québec des frontières établies par les traités, il importe de rappeler que la majorité des frontières du Québec actuel sont principalement internes au Canada, d'où l'utilité

30. Loi sur la souveraineté $d u$ Québec, Avant-projet de loi, 1ère session, 35e législature (Québec).

31. Rapport des Commissaires, vol. 6, déc. 1971, p. 165, n 14.

32. T.M. FRANCK, loc. cit., supra, note 9, à la p. 399; H. DORION, «Les frontières du Québec: l'état de la question» reproduit dans Recueil des exposés et études soumis à la commission d'étude des questions afférentes à l'accession du Québec à la souveraineté, volume 1, tome 2, 1992, pp. 362-363. 
Les frontières terrestres

(1994-95) 25 R.D.U.S. d'un Québec souverain à la lumière

du droit international contemporain

d'examiner si de telles frontières se voient conférer une protection par le droit international.

\section{Chapitre II L'accession à la souveraineté du Québec et l'intangibilité des frontières protégées par l'uti possidetis juris}

Les instruments juridiques qui déterminent les frontières internes d'un état fédéré ne constituent pas des traités. Ce sont généralement des textes constitutionnels ou législatifs qui définissent les limites internes. Dès lors, les règles relatives à la succession d'États en matière de traités ne sont pas applicables. En revanche, le droit international comporte une règle qui protège les limites intérieures des États destinées à devenir des frontières. Il s'agit de l'uti possidetis juris, qui sera applicable pour déterminer les futures frontières d'un Québec souverain avec le Canada.

\subsection{L'universalité et le renforcement de la règle de l'uti posside- tis}

Le principe de l'uti possidetis juris fut conçu en 1810 dans le but de permettre aux colonies portugaises et espagnoles d'Amérique latine d'accéder à l'indépendance en préservant l'intégrité du territoire occupé et le maintien des frontières jadis internes ${ }^{33}$. Depuis cette époque, ce principe a connu de nombreuses applications ${ }^{34}$, notamment au cours de la deuxième moitié du $\mathrm{XX}^{\mathrm{e}}$ siècle dans le cadre de la décolonisation africaine et asiatique. D'ailleurs, la Déclaration du Caire de 1964, adoptée par l'Organisation de l'unité africaine,

33. La locution latine traduit cette volonté de préserver le territoire dans son intégralité, lors de l'accession à l'indépendance : «Uti possidetis, ita possideatis» («Comme tu as possédé, tu continueras à posséder»). J. DE PINHO CAMPINO, «L'actualité de l'Uti possidetis», dans La frontière, Paris, Société Française pour le Droit International, Colloque de Poitiers, Éditions A. Pedone, 1980, p. 95.

34. Id., p. 105, J. DE PINHO CAMPINO affirme : «En plus de ces deux vagues principales, le principe semble avoir été appliqué, outre le cas des Républiques sud-américaines, lors de l'accession à l'indépendance des États-Unis d'Amérique, de la Belgique, de la Pologne, de la Tchécoslovaquie, de la Finlande, de l'État libre d'Irlande, des États Baltes, du Panama, du Pakistan, de l'Angola, entre autres». Voir aussi P. GIRARD, «L'intégrité du territoire québécois dans l'hypothèse de la souveraineté», (1992) 6 R.J.E.U.L. 25; M.G. KOHEN, «L'Uti possidetis revisité : l'arrêt du 11 septembre 1992 dans l'affaire El Salvador/Honduras», (1993) 97 R.G.D.I.P. 939. 
a procédé à la codification de ce principe dans le but d'empêcher que les frontières africaines arbitrairement tracées par les métropoles ne deviennent la source de nouveaux conflits. Le principe de l'uti possidetis juris a de plus été consacré par la jurisprudence internationale ${ }^{35}$.

L'évolution de ce principe s'est poursuivie ces dernières années et l'on peut prétendre à juste titre aujourd'hui qu'il a une portée universelle qui a d'ailleurs été renforcée récemment.

\subsubsection{L'universalité de la règle de l'uti possidetis}

Ainsi, le principe de l'uti possidetis juris ou de l'intangibilité des frontières a vu son champ d'application s'élargir. Cette évolution a été confirmée par la Cour Internationale de Justice, qui a affirmé dans l'affaire Burkina Faso c. République du Mali ${ }^{36}$ :

«Ce principe ne revêt pas pour autant le caractère d'une règle particulière, inhérente à un système déterminé de droit international. Il constitue un principe général, logiquement lié au phénomène de l'accession à l'indépendance, où qu'il se manifeste. Son but évident est d'éviter que l'indépendance et la stabilité des nouveaux États ne soient mises en danger par des luttes fratricides...» ${ }^{37}$ (l'italique est de nous)

Cette règle de l'uti possidetis fait en sorte que «les frontières établies par l'État cédant $[. .$.$] obligent l'État successeur { }^{38}$. Les frontières internes acquièrent donc le statut de frontières protégées par le droit international une fois que l'état fédéré a accédé à l'indépendance. L'invocation de cette règle coutumière par des états fédérés facilite son application en raison du découpage interne préexistant dans l'État fédératif.

35. V. Affaire du Temple de Preah Vihear (Cambodge c. Thaïlande), arrêt du 15 juin 1962, C.I.J., Recueil 1962, p. 6. Ce principe a été développé par la jurisprudence, voir supra, note 17.

36. Supra, note 17, p. 554.

37. Id., p. 565.

38. M. BETTATI, «Souveraineté et succession d'États» dans R.J. DUPUY et al., La souveraineté au XXe siècle, Paris, coll. U., Armand Colin, 1971, p. 66. 
Les récentes accessions à la souveraineté permettent de constater la mise en oeuvre de cette règle et l'importance qu'elle revêt en pratique dans la communauté internationale. La majorité des états fédérés qui ont récemment accédé à l'indépendance, ont établi leur souveraineté sur le territoire bordé par leurs anciennes limites. D'ailleurs, le Conseil des États Baltes, dans une déclaration du 27 juillet 1990, affirmait ce qui suit :

«4. That the three Baltic states do not have any territorial, property or other claims against one another.» ${ }^{39}$

N'ayant pas de revendications territoriales, ces entités ont donc accepté d'accéder à la souveraineté à l'intérieur de leurs frontières.

La Biélorussie proclame également sa souveraineté dans les frontières et limites administratives qui étaient les siennes avant l'indépendance, et les problèmes relatifs aux frontières devraient trouver une solution dans un accord mutuel entre la Biélorussie et le pays contigu, accord qui sera ratifié par le parlement de Biélorussie ${ }^{40}$.

Le Parlement ukrainien proclame quant à lui :

«The state sovereignty of the Ukraine as the supreme, independent, absolute, and indivisible authority of the republic within the borders of its territory and independent and equal in all foreign relations. ${ }^{41}$ (l'italique est de nous)

L'Ukraine a d'ailleurs signé avec la Moldavie, le 25 octobre 1992, un traité d'amitié qui reconnaît l'intangibilité des frontières. De plus, le «pacte de stabilité en Europe» signé par les 52 pays membres de l'O.S.C.E. à la fin mars 1995 vise le maintien des frontières existantes en Europe centrale, orientale et

39. Statement by the Council of Baltic States (Jurmala, 27 juillet 1990), reproduit dans (1992) 5 Constitutions of the countries of the world 271.

40. On The State Sovereignty of the Belorussian SSR, (Minsk, 27 juillet 1990), reproduit dans (1992) 4 Constitutions of Dependencies and Special Sovereignties 35-38.

41. Declaration on Ukraine's State Sovereignty (resolution of the 28th Congress of the Ukrainian Communist Party), reproduit dans (1992) 4 Constitutions of Dependencies and Special Sovereignties 89. 
dans les États baltes, là où les conflits armés n'ont pas éclaté, par des accords bilatéraux de bon voisinage et d'amitié.

Le traité instituant la Communauté des États Indépendants (C.É.I.) semble aussi confirmer l'accession à l'indépendance des États qui en sont membres dans le cadre des limites préexistantes, ou dans des limites qui ont fait l'objet de modifications par voie d'accord ${ }^{42}$.

La règle de l'uti possidetis a également trouvé application dans l'exYougoslavie. La Commission d'arbitrage de la Conférence de paix en Yougoslavie constate la portée générale et universelle de la règle coutumière. Elle applique ainsi les principes du respect du statu quo territorial et de l'uti possidetis juris à l'accession à l'indépendance de la Croatie ${ }^{43}$ et de la BosnieHerzégovine. Les autorités bosniaques ont assuré d'ailleurs à la Commission qu'elles n'ont pas de revendications territoriales ${ }^{44}$, ce qu'ont fait également la République de Macédoine ${ }^{45}$, et la Slovénie. Cette dernière s'est engagée de plus à respecter l'inviolabilité des limites territoriales ${ }^{46}$. D'autre part, l'article 2 de la Charte constitutionnelle fondamentale de la Slovénie démontre que celle-ci a accédé à la souveraineté à l'intérieur du cadre établi par les frontières externes et internes préexistantes. Malgré un discours qui prônait au début l'intangibilité des frontières internes et externes, la communauté internationale s'est laissée dépasser par une escalade d'événements violents en ex-Yougoslavie. L'impuissance de la communauté internationale à résoudre le conflit dans l'exYougoslavie illustre à quel point il peut être difficile de faire respecter en

42. Armenia-Azerbaijan-Belarus-Kazakhstan-Kyrgystan-Moldavia-RussianFederationTajikistan-Turkmenistan-Uzbekistan-Ukraine : Agreements establishing the Commonwealth of Independent States (Minsk, 8 décembre 1991), reproduit dans (1992) 31 I.L. M. 138, art. 5 .

43. La Croatie a accédé à l'indépendance dans ses frontières internationales et internes préexistantes, voir Constitutional Decision on the Sovereignty and independence of the Republic of Croatia, supra, note 20, à la p. 123-124, art. IV.

44. Avis $n^{\circ} 4$ de la Commission d'arbitrage pour la Yougoslavie, reproduit en langue anglaise dans (1992) 31 I.L.M. 1501.

45. Avis $n^{\circ} 6$ et $n^{\circ} 7$ de la Commission d'arbitrage pour la Yougoslavie, reproduits dans (1992) 31 I.L.M. 1507 et s. et voir la Déclaration de l'Assemblée de la République, 17 septembre 1991.

46. Voir la déclaration d'indépendance du 25 juin 1991, et la demande de reconnaissance du 19 décembre. 
pratique des principes de droit sur des sujets aussi passionnels que celui de la délimitation des frontières.

Ces nouveaux États déclarent aussi leur territoire indivisible et leurs frontières inviolables, seuls les changements auxquels ils auront donné leur accord étant permis. Ils peuvent d'ailleurs s'appuyer en cela sur la Déclaration sur la Yougoslavie, dans laquelle la Communauté européenne et ses États membres affirment ne jamais vouloir «reconnaître des changements de frontières qui n'auraient pas été agréés par des moyens pacifiques et par voie d'accords ${ }^{47}$. Aucune protection légitime ne sera accordée à de telles frontières litigieuses. Dans son troisième avis, la Commission d'arbitrage de la Conférence de paix en Yougoslavie confirme cette position :

«Deuxièmement - Les démarcations entre la Croatie et la Serbie ou entre celleci et la Bosnie-Herzégovine, ou, éventuellement, entre d'autres États indépendants limitrophes entre eux, ne pourront être modifiées que par accord libre et mutuel» ${ }^{48}$.

Les prises de position en ce sens se sont multipliées ${ }^{49}$ et s'appliquent également à l'égard de l'ex-Union soviétique. On vise ainsi à éliminer l'emploi de la force par le nouvel État qui voudrait étendre son territoire, ou par l'État fédératif prédécesseur susceptible de vouloir récupérer des parties de son territoire antérieur. Malgré ce courant, la communauté internationale n'a pas fait obstacle à l'invasion de la République tchétchène pas les troupes russe le 11 décembre 1994. Par ailleurs, la communauté internationale a accepté en vue d'éviter l'extension du conflit yougoslave, la morphologie du territoire bosniaque tel que délimité par les conquêtes territoriales serbes. En effet, après le rejet par les Serbes du plan de paix Vance-Owen (2 janvier 1993) visant le découpage de la Bosnie en dix provinces autonomes avec répartition ethnique, cinq membres de l'O.N.U. (France, États-Unis, Russie, Royaume-Uni, Espagne) ont entériné

47. Déclaration sur la Yougoslavie (Réunion ministérielle extraordinaire, Bruxelles, 27 août 1991), reproduit dans (1992) 96 R.G.D.I.P. 263.

48. Avis $n^{\circ} 3$ de la Commission d'arbitrage pour la Yougoslavie, supra, note 21, p. 268.

49. T.M. FRANCK, loc. cit., supra, note 9, p. 415-416; voir également A. PELLET, «The Opinions of the Badinter Arbitration Committee : A Second Breath for the SelfDetermination of Peoples» (1992) 3 European Journal of International Law 180. 
de facto les conquêtes serbes le 22 mai 1993 en acceptant «un plan d'action commun» qui instaurait, entre autres, six «zones de sécurité» sous protection des casques bleus de la Force de protection des Nations Unies. Cette prise de position, même si elle révèle le souci de rétablir rapidement la paix, constitue un précédent d'autant plus dangereux qu'elle s'est manifestée en période de revendications territoriales en Europe, par des groupes voulant modifier les frontières par la force. Elle a contribué à discréditer la Communauté européenne et l'O.N.U. La situation en ex-Yougoslavie est toujours explosive, et en 1995 un quart du territoire de la Croatie est demeuré occupé par les forces serbes de la République autoproclamée de Krajina où stationnent des casques bleus.

Ainsi, nous pouvons conclure en confirmant que le principe de l'uti possidetis juris fait sans doute partie de la coutume, dans la mesure où il est consacré par une pratique plutôt uniforme et constante des États, que ceux-ci acceptent comme étant le droit (opinio juris). Si les précédents sont assez récents, un bref laps de temps n'est pas un obstacle à la création d'une coutume comme l'a affirmé la Cour Internationale de Justice dans l'affaire portant sur le Plateau continental de la mer du Nord ${ }^{50}$. Dans un tel domaine, les précédents n'ont pas à être très nombreux.

\subsubsection{Le renforcement de la règle de l'uti possidetis}

La règle de l'uti possidetis voit son application renforcée si d'autres principes de droit international et de droit constitutionnel viennent s'y greffer. En effet, la portée de cette règle paraît s'intensifier lorsque l'ancienne loi constitutionnelle de l'État dont faisait jadis partie l'état fédéré va dans le même sens que le principe de l'intangibilité des frontières. Il en découle un plus grand respect du droit international. Ceci découle de l'avis $n^{\circ} 3$ de la Commission d'arbitrage de la Conférence de paix en Yougoslavie selon lequel le principe de l'uti possidetis juris «trouve d'autant plus aisément à s'appliquer entre les Républiques que, en vertu des alinéas 2 et 4 de l'article 5 de la Constitution de la R.S.F.Y., il avait été décidé que la consistance des territoires et les limites des Républiques ne pourraient être modifiées sans leur accord» ${ }^{51}$. 
Si l'uti possidetis juris s'avère une règle juridique visant à préserver l'assiette territoriale de l'entité fédérée qui accède à la souveraineté, il y a lieu de l'appliquer au cas particulier du Québec.

\subsection{L'application de la règle de l'uti possidetis aux frontières intérieures du Québec}

En application de la règle de l'uti possidetis, le Québec, une fois souverain, bénéficierait d'une protection de ses anciennes frontières internes. Cette protection créerait pour le Canada et les autres États de la communauté internationale une obligation de respecter les limites du Québec. L'application de cette règle sera d'ailleurs renforcée dans la mesure où la Constitution canadienne protège l'intangibilité des frontières internes au Canada.

Deux lois constitutionnelles canadiennes mentionnent, sans équivoque possible, qu'un changement de délimitation du territoire provincial nécessite l'accord du Parlement fédéral et des législatures provinciales concernées. L'article 3 de la Loi constitutionnelle de $1871^{52}$, d'application large, vise l'ensemble des limites territoriales d'une province et stipule :

«The Parliament of Canada may from time to time, with the consent of the Legislature of any Province of the said Dominion, increase, diminish, or otherwise alter the limits of such Province, upon such terms and conditions as may be agreed to by the said Legislature, and may, with the like consent, make provision respecting the effect and operation of any such increase or diminution or alteration of territory in relation to any Province affected thereby». (l'italique est de nous)

De plus, l'article 43 a) de la Loi constitutionnelle de $1982^{53}$ consacre la règle du consentement des provinces concernées pour tout changement des limites de leur territoire, mais restreint son champ d'application aux modifications des frontières interprovinciales ${ }^{54}$. Il se lit ainsi :

52. 34 \& 35 Vict., R.-U, c. 28.

53. $\quad$ Annexe B de la Loi de 1982 sur le Canada, 1982, R.-U., c. 11.

54. Voir H. DORION, loc. cit., supra, note 32, à la p. 359; H. BRUN et G. TREMBLAY, op. cit., supra, note 27, à la p. 139; T.M. FRANCK, loc. cit., supra, note 9, à la p. 387-389; P. GIRARD, loc. cit., supra, note 34, à la p. 33. 
«Les dispositions de la Constitution du Canada applicables à certaines provinces seulement ne peuvent être modifiées que par proclamation du gouverneur général sous le grand sceau du Canada, autorisée par des résolutions du Sénat, de la Chambre des communes et de l'assemblée législative de chaque province concernée. Le présent article s'applique notamment :

a) aux changements du tracé des frontières interprovinciales; [...]»

Ainsi, l'accord de l'Assemblée nationale du Québec est nécessaire dans l'hypothèse où le Parlement fédéral voudrait modifier les limites interprovinciales ou la grandeur du territoire québécois. En effet, les deux lois coexistent car la Loi constitutionnelle de 1982 n'abroge ni de façon expresse, ni par son but la Loi constitutionnelle de $1871^{55}$. La Constitution canadienne garantit ainsi l'intégrité territoriale du Québec en tant que province canadienne; elle impose des conditions aux modifications des limites séparant le Québec des autres provinces et à celles séparant le Québec des territoires.

Les limites actuelles du Québec sont ainsi protégées par la Constitution canadienne et son territoire étatique l'est en vertu de l'application de l'uti possidetis juris. Cela se traduit par une obligation de maintien des frontières interprovinciales actuelles du Québec, ainsi que par une protection de l'intégrité du territoire intérieur du Québec actuel, et en particulier des territoires nordiques acquis en 1898 et en 1912.

\subsubsection{L'intangibilité des frontières intérieures actuelles du Québec}

\section{- La frontière Québec / Nouveau-Brunswick}

La frontière séparant le Québec du Nouveau-Brunswick est le résultat de l'application de la Proclamation Royale de 1763, et de l'Acte de Québec de 1774. En 1851, une loi britannique ${ }^{56}$ mit fin à une controverse concernant

55. J. WOEHRLING, Les aspects juridiques de la redéfinition du statut politique et constitutionnel du Québec, Commission sur l'avenir politique et constitutionnel du Québec, document de travail n² 2, Québec, 1991, pp. 58-59.

56. An Act for the Settlement of the Boundaries between the Provinces of Canada and New Brunswick, 14-15 Vict., R.-U., c. 63. 
l'interprétation de ces textes et décrivit les frontières. Il s'agit d'une frontière complexe, mais heureusement démarquée. La frontière suit la ligne de partage des eaux, contourne les «seigneuries de Madawaska et de Temiscouata», longe le 48e parallèle, puis le milieu ou thalweg des rivières Matapédia et Ristigouche. Cette frontière posait un problème qui fut résolu en octroyant les îles au Nouveau-Brunswick. La ligne se situe entre ces îles et le rivage québécois. Notons que les lits des rivières peuvent changer avec le temps et, par conséquent, les frontières aussi. Dans de telles circonstances «la frontière suit les changements progressifs et continus des lignes géomorphologiques mais non les changements brusques impliquant des espaces relativement importants» ${ }^{57}$. La frontière se prolonge et se situe au milieu de la baie des Chaleurs. Le seul problème est de savoir où elle se termine, vu l'absence d'accord ou de courant judiciaire réglant le statut des eaux du golfe du Saint-Laurent ${ }^{58}$.

\section{- La frontière Québec / Ontario}

L'actuelle frontière entre le Québec et l'Ontario prend sa source dans un arrêté en conseil impérial de 1791 qui suit l'Acte Constitutionnel de $1791^{59}$. Ce texte établissait la frontière comme suit :

«une ligne joignant le Saint-Laurent à l'Outaouais, en passant par les limites ouest des seigneuries de Nouvelle-Longueuil, Vaudreuil et Rigaud, suivant ensuite l'Outaouais jusqu'au lac Temiscamingue pour se diriger finalement, à partir de la tête de ce dernier, en droite ligne en direction nord, «jusqu'à la frontière de la baie d'Hudson.» ${ }^{60}$

Suivirent d'autres lois qui précisèrent la frontière, dont la loi impériale de $1889^{61}$. Pour établir la frontière, la loi reprenait les limites décrites dans la loi de 1791 pour en préciser la limite nord en la situant sur la côte de la baie James.

57. H. DORION, loc. cit., supra, note 32, à la p. 362.

58. H. BRUN et G. TREMBLAY, op. cit., supra, note 27, à la p. 140.

59. S.R.C. 1970, appendice II, p. 139.

60. H. BRUN, op. cit., supra, note 27, à la p. 25.

61. Acte à l'effet de déclarer les limites de la province d'Ontario, dans la puissance du Canada, 52 \& 53 Vict., R.-U, c. 28. 
Quant à la frontière concernant la région du lac Témiscamingue et de la rivière Outaouais, elle longeait «le milieu du chenal principal» ${ }^{62}$.

Le Québec devenu souverain pourrait se heurter à certains obstacles concernant la garantie de cette frontière. En effet, la compétence sur 18 îles du Saint-Laurent n'est pas encore clairement établie entre le Québec et l'Ontario, puisque les démarcations qui ont été effectuées par une entente administrative mettant fin au conflit n'ont pas été entérinées par le législateur. Quant au point de jonction entre le Québec, l'Ontario et les Territoires du Nord Ouest, il est situé non dans la baie James, mais sur le littoral ${ }^{63}$. Notons l'existence de problèmes frontaliers et de démarcation entre la frontière Québec / Ontario, dont l'importance est mineure dans la mesure où la délimitation de cette même frontière a été établie, et donc déjà connue. ${ }^{64}$

\section{- La frontière Québec / Terre- Neuve (Labrador)}

Le Labrador, situé au nord-est du Québec, a été rattaché à Terre-Neuve puis au Québec de façon alternative. En 1825, il fut partagé et la partie au sud du 52e parallèle fut attribuée au Québec par une loi impériale ${ }^{65}$. La frontière qui sépare actuellement le Québec de Terre-Neuve tire son origine d'une décision du Comité judiciaire du Conseil Privé de Londres rendue en $1927^{66}$, au profit de Terre-Neuve. Ayant force légale, elle s'impose au Québec qui ne possède aucun argument juridique pour en contester la valeur et exiger la révision de cette décision. En effet, plusieurs arguments ont été avancés afin d'étayer les revendications québécoises mais aucun d'eux n'a véritablement de valeur. Mentionnons l'absence de preuve à l'effet que les juges eurent des intérêts pécuniaires directs dans l'octroi du Labrador à Terre-Neuve. Le Québec fut partie au litige dans la mesure où l'intervention du Canada dans cette affaire faisait suite à la demande du Québec. Par ailleurs, ce qui fut accordé à TerreNeuve le fut au-delà de ce que proposaient les cartographies, mais correspondait néanmoins aux revendications textuelles de Terre-Neuve. Le Québec a de plus

62. H. BRUN, op. cit., supra, note 27, aux pp. 25-26.

63. La frontière entre le Québec et les Territoires du Nord Ouest est la «ligne de rivage».

64. H. DORION, loc. cit., supra, note 32, à la p. 363.

65. British North America Act, 1825, 6 Geo. IV, c. 59 (R.-U.).

66. $\quad$ Re Labrador Boundary, [1927] 2 D.L.R. 401 (C.P.). 
réaffirmé et reconnu l'existence de cette frontière à maintes reprises et par des moyens forts différents (lois ${ }^{67}$, déclarations ministérielles, cartographies...) même si en revanche, il l'a contestée à de nombreuses reprises. Le fait que le Conseil Privé était juge et partie n'a pas constitué en soi un obstacle à la valeur du jugement, puisque les parties étaient informées. Quant à la partie du territoire située entre la ligne de partage des eaux et le 52e parallèle, elle pourrait être l'objet de négociations pour qu'elle fasse partie du territoire québécois. S'agissant d'une frontière délimitée mais peu démarquée, seules des négociations pourraient aboutir à un nouveau tracé de la frontière en l'absence de solutions judiciaires possibles ${ }^{68}$.

\section{- La frontière Québec / Territoires du Nord-Ouest}

La frontière entre le Québec et les Territoires du Nord-Ouest est située à la rive, depuis l'extension des frontières de 1912. Cette délimitation, comme le souligne l'auteur H. Dorion ${ }^{69}$, a soulevé des difficultés de deux ordres :

- La ligne de rivage a été établie à la ligne des basses eaux afin de situer la frontière, et ce, grâce à une entente entre le Québec, les Territoires du NordOuest et les autorités fédérales. Malgré l'absence de codification constitutionnelle, elle est reprise par la Convention de la Baie-James et du Nord québécois. Ainsi les îles dites d'estran (îles rattachées au continent lors de la marée basse) appartiennent au territoire du Québec. Le problème se pose alors de savoir «jusqu'où vers l'intérieur [...] la ligne de la basse mer

67. Une loi reconnait dans son annexe spécifiquement cette frontière dans la mesure où elle «se réfère à la frontière Québec-Labrador Terre-Neuvien comme étant située à la ligne du partage des eaux "qui forme frontière entre le Québec et le Labrador Terre-Neuvien"(sic.)» (Loi de 1946 sur le développement minier).

68. Voir H. DORION, loc. cit., supra, note 32, aux pp. 369-371 (pour plus de précisions); L. PATENAUDE, Le Labrador à l'heure de la contestation, Montréal, P.U.M., 1972; H. BRUN, «Le Québec et la décision du Conseil Privé de 1927 concernant le Labrador», op. cit., supra, note 27, à la p. 96; voir également le Rapport de la Commission d'étude sur l'intégrité du territoire du Québec, la «frontière du Labrador», (1971), vol 3.4 De la reconnaissance des frontières en droit Québécois (par L. Patenaude), vol. 3.5. L'opinion du Conseil Privé (1927) et les possibilités de recours (par H. Brun, 1969), vol. 3.7.3. Les attitudes du Québec face à la décision et au tracé de 1927. Loi de l'Union de Terre-Neuve au Canada, S.C. 1949 (13 Geo. VI), c. 1.

69. H. DORION, loc. cit., supra, note 32, aux pp. 364-367. 
remonte». Des difficultés relatives à la démarcation demeurent, vu la nécessité de préciser davantage la délimitation des frontières.

- Par ailleurs, une situation problématique se pose à l'égard des «îles littorales, c'est-à-dire celles qui ne sont pas rattachées au territoire à marée basse et celles qui ne sont ni dans les estuaires ni dans les baies profondes, [qui] font donc incontestablement partie des Territoires du Nord Ouest.» ${ }^{70}$

C'est ce que nous indique la loi. Il importera donc de départager les îles entre celles appartenant au Québec et celles appartenant aux Territoires du Nord-Ouest.

\subsubsection{La protection de l'intégrité du territoire intérieur du Québec}

Diverses thèses ont été avancées qui prétendent qu'un Québec souverain ne posséderait pas l'intégrité du territoire dont il bénéficiait en tant que province et qu'il pourrait être privé en accédant à la souveraineté des territoires acquis en 1898 et 1912.

L'Acte de la terre de Rupert de $1868^{71}$ permit à la Compagnie de la Baie d'Hudson de céder au Canada ses terres, droits et privilèges. Le Parlement impérial, sous l'effet des controverses engendrées par la création du Manitoba, adopta la Loi constitutionnelle de $1871^{72}$. Par le biais de son article 3, le Parlement fédéral obtint la possibilité de modifier les frontières d'une province seulement avec son accord. Cette procédure fut suivie en 1898 lors d'une extension du territoire québécois vers le Nord. Des lois provinciales ${ }^{73}$ et fédérales $^{74}$ furent adoptées dans le but de confirmer l'octroi de la terre de Rupert au Québec. En 1912, le Québec bénéficia d'une augmentation

70. $\quad I d .$, p. 366

71. $31 \& 32$ Vict. 6 , R.-U., c. 105.

72. $34 \& 35$ Vict., R.-U., c. 28.

73. Loi concernant la délimitation des frontières nord-ouest et nord-est de la province de Québec, S.Q. 1898, c. 6.

74. Acte concernant la délimitation des frontières nord-ouest, nord et nord-est de la province du Québec, S.C. 1898 , c. 3. 
substantielle de son territoire par des lois de même nature ${ }^{75}$, puisqu'il se vit octroyer le reste de la péninsule de l'Ungava. La frontière fut alors établie le long du rivage. Les lois exigeaient le respect de certaines conditions qui furent cependant abrogées quelques années plus $\operatorname{tard}^{76}$.

Certains auteurs ${ }^{77}$ ont prétendu que l'acquisition des territoires était sujette au respect de conditions. Parmi ces conditions, certains invoquent celles de l'article 2c) des lois de 1912 qui prévoit :

«c) La province de Québec reconnaîtra les droits des habitants sauvages dans le territoire ci-dessus décrit dans la même mesure, et obtiendra la remise de ces droits de la même manière, que le gouvernement du Canada a ci-devant reconnu ces droits et obtenu leur remise, et ladite province supportera et acquittera toutes les charges et les dépenses se rattachant à ces remises ou en résultant;»

Ces auteurs soutiennent que, vu le non respect de ces conditions par le Québec, le Canada serait justifié de vouloir récupérer ces territoires. D’après le professeur H. Brun l'alinéa c de l'article 2 a pour effet de réduire l'obligation du Québec de reconnaître les droits des autochtones à une obligation de ne pas nuire à leurs droits. Il poursuit :

«Pour ce qui est du 2e volet de 2c), soit l'obligation d'obtenir la rétrocession des droits des autochtones sur le territoire de 1912, il n'est rien d'autre qu'une délégation inconstitutionnelle de pouvoir.» ${ }^{78}$

75. Au fédéral : Loi à l'effet d'étendre les frontières de la province de Québec, S.C. 1912, c. 45. Au Québec : Loi concernant l'agrandissement du territoire de la province de Québec par l'annexion de l'Ungava, S.Q. 1912, c. 7.

76. P. GIRARD, loc. cit., supra, note 34, aux pp. 34-37; H. BRUN et G. TREMBLAY, op. cit., supra, note 27, à la p. 139.

77. D.J BERCUSON et B. COOPER, Deconfederation-Canada without Quebec, Toronto, Key Porter Books, 1991; S.A. SCOTT, «Autodétermination, sécession, division, légalité : observations» reproduit dans Recueil des exposés et études soumis à la Commission d'étude des questions afférentes à l'accession du Québec à la souveraineté, volume 1, tome 2, 1992, à la p. 463; D. L. VARTY, Who gets Ungava?, Vancouver, Varty \& Company Printers, 1991.

78. H. BRUN, «Les conséquences territoriales de l'accession du Québec à la souveraineté», reproduit dans Recueil des exposés et études soumis à la Commission d'étude des questions afférentes à l'accession du Québec à la souveraineté, volume 1, tome 2, 1992, à la p. 486; 
Ceci en raison de la compétence constitutionnelle du gouvernement fédéral relativement aux Indiens et à leurs terres. Seule une loi impériale aurait pu opérer un tel changement. Enfin, les conditions assorties à l'octroi du territoire de 1912, mentionnées dans les lois provinciales et fédérales, furent abrogées par les lois de chacun des paliers de gouvernement ${ }^{79}$ qui confirmèrent la Convention de la Baie James et du Nord québécois (11 novembre 1975). Aucune revendication ne peut aujourd'hui être fondée sur la base de conditions légales inexistantes. Les droits des autochtones sur ce territoire ont été éteints.

Des auteurs ${ }^{80}$ ont prétendu que les territoires de 1898 et de 1912 furent acquis par le Québec en tant que province de la fédération canadienne, et que par conséquent une sécession amputerait le territoire québécois de cette région suite à la perte de son statut de province. Afin de rejeter une telle prétention, le professeur $\mathrm{H}$. Brun ${ }^{81}$ stipule que vouloir retirer unilatéralement des territoires sur lesquels le Québec peut légiférer, pour des raisons de non respect des conditions fédératives ou autres, est imposer une sanction propre au droit civil, droit régissant les rapports entre individus. La situation qui nous préoccupe implique des questions de souveraineté et de territoire, elle est donc reliée au droit constitutionnel. Le pouvoir pour le Québec de légiférer sur ces territoires provient d'amendements constitutionnels. Par conséquent :

«Ce pouvoir [ne peut] être retiré ou transféré autrement que par l'exercice formel du pouvoir constituant expressément prévu à cette fin par la Constitution

P. GIRARD, loc. cit., supra, note 34, aux pp. 37-38.

79. Au fédéral : Loi sur le règlement des revendications des autochtones de la Baie James et du Nord québécois, S.C. 1976-77, c. 32, a. 7. Au Québec: Loi approuvant la Convention de la Baie James et du Nord québécois, L.Q. 1976, c. 46, a. 5. Pour avoir plus d'information sur la Convention de la Baie James, voir S. GRAMMOND, «Les effets juridiques de la Convention de la Baie James au regard du droit interne canadien et québécois», (1992) 37 R.D. McGill 761.

80. D.J BERCUSON et B. COOPER, op. cit., supra, note 77; W. F. SHAW et L. ALBERT, Partition: The Price of Quebec's Independence, Montréal, Thornhill Publishing, 1980, p. 204; Les Cris dans Status and rights of the James Bay Crees in the context of Quebec's secession from Canada submitted by the Grand Council of the Crees (of Quebec) to the Commission on Human Rights of the United Nations, February 1992, p. 83 (ci-après dénommé Status and rights of the James Bay Crees).

81. H. BRUN, loc. cit., supra, note 78, à la p. 482. 
ou par l'exercice formel du droit à l'autodétermination par la collectivité ellemême.» ${ }^{82}$

Par ailleurs, le territoire de l'Ungava fut rattaché en 1870 au Canada et non acheté par le gouvernement fédéral canadien à la Compagnie de la Baie d'Hudson comme le prétendent certains. L'entente fédérative de 1867 prévoyait l'attribution éventuelle des territoires, dont celui de la terre de Rupert, aux provinces fondatrices et non au gouvernement fédéral. Le gouvernement fédéral n'en étant pas propriétaire, n'a pu en faire «cadeau» au Québec.

Quant aux auteurs de l'opinion collective sollicitée par la Commission d'étude sur la souveraineté ${ }^{83}$, ils affirment qu'un retrait de ces territoires impliquerait que le Québec reprenne la partie nord-est qu'il avait cédée au Canada en échange du territoire de 1898. Ce genre d'argumentation quant au retrait des territoires ne trouve pas de fondements juridiques.

La thèse voulant que le Québec accède à l'indépendance à l'intérieur des «limites du Canada français» antérieures à 1763 est illusoire, les limites de cette époque étant difficilement identifiables, et cette thèse résulterait en une violation du principe de l'intangibilité des frontières, vu entre autres l'empiétement qu'elle produirait sur le territoire des États-Unis ${ }^{84}$.

Les arguments constitutionnels invoqués par les promoteurs de ces diverses thèses voulant le retrait des territoires ne sont guère convaincants et ne sauraient d'ailleurs être valablement opposés aux arguments de droit constitutionnel et de droit international fondés sur l'application de l'uti possidetis juris. À cet égard, nous partageons la thèse présentée dans l'opinion collective préparée pour la Commission d'étude sur la souveraineté reprenant l'affaire Burkina Faso, voulant qu'il faille prendre en considération «l'instantané territorial», donc la date de l'accession à la souveraineté afin de connaître les frontières d'un Québec souverain.

82. Ibid.

83. T.M. FRANCK, loc. cit., supra, note 9, à la p. 405.

84. Id., p. 402. 
«Quelles qu'aient été les circonstances et les raisons qui ont conduit à la fixation des limites territoriales existant au moment de l'accession à l'indépendance, celle-ci «arrête la montre sans lui faire remonter le temps» ${ }^{85}$. (l'italique est de nous)

À la lumière du droit international, le territoire provincial du Québec formerait son territoire étatique une fois le Québec devenu indépendant. L'Avant-projet de Loi sur la souveraineté du Québec confirme cette assiette territoriale en édictant à son article 4 que :

«Le Québec conserve les frontières qui sont les siennes au sein de la Confédération canadienne, au moment de l'entrée en vigueur de l'article 1 [c'est-à-dire une fois le Québec devenu souverain]. Il exerce ses compétences sur les zones maritimes et les territoires adjacents à ses côtes selon les modalités et dans les conditions prévues par les règles du droit international.»

Ainsi, ses anciennes frontières internes demeureraient les mêmes grâce à l'uti possidetis juris et sa frontière internationale serait maintenue.

Mais l'intégrité du territoire québécois est-elle susceptible d'être menacée par l'exercice du droit à l'autodétermination des nations autochtones vivant sur le territoire du Québec?

\section{Chapitre III L'accession du Québec à la souveraineté et le problème de l'intégrité du territoire québécois en cas de revendica- tions autochtones}

Certains auteurs soutiennent que tous les peuples ont le droit de faire sécession, car il est l'une des modalités d'exercice du droit à l'autodétermination ${ }^{86}$. D'autres affirment que l'accession à l'indépendance est «une question de pur fait que le droit international ne fonde ni ne réprouve : il en prend acte» ${ }^{87}$. Pour ces derniers, seuls les peuples coloniaux et «reconnus

85. Id., p. 404. L'affaire du différend frontalier terrestre, insulaire et maritime, supra, note 17, p. 388 semble, à tort vu la pratique récente des États nouvellement indépendants, privilégier l'approche contraire : celle voulant que l'uti possidetis soit un principe rétroactif.

86. D. TURP, loc. cit., supra, note 4.

87. T.M. FRANCK, loc. cit., supra, note 9. 
comme tels par les Nations Unies» auraient droit de se former un État en invoquant le droit des peuples à disposer d'eux-mêmes ${ }^{88}$. Nous considérons que le droit à l'autodétermination est le moteur des revendications sécessionnistes de tous les peuples mais que le passage à la formation d'un État se révélera une question de fait, donc de contrôle effectif advenant plusieurs revendications territoriales par divers peuples, sur un même territoire.

\subsection{Les nations autochtones : des peuples minoritaires}

Différentes thèses ont été soulevées afin de déterminer si les autochtones auraient les droits attribués aux peuples. Si des juristes refusent tout droit à l'autodétermination aux autochtones parce qu'ils ne formeraient pas un ou des peuples au sens du droit international, d'autres stipulent que leur participation aux institutions du pays serait de nature à épuiser le droit à l'autodétermination qu'ils avaient. Est également invoquée la situation coloniale dans laquelle se trouveraient les autochtones; ces derniers par conséquent pourraient invoquer, outre le principe de l'égalité des droits des peuples, leur droit à l'autodétermination et donc accéder sur la base de ce droit à l'indépendance.

En l'absence d'une définition précise du mot «minorité», le droit international n'octroie pas les mêmes droits à une minorité qu'à un peuple. En effet, les règles internationales instaurées veulent essentiellement protéger les droits des minorités ethniques, linguistiques ou religieuses à l'intérieur de l'État sans toutefois leur accorder le droit de se constituer en État. Si les minorités revendiquent des territoires et parfois accèdent à l'indépendance, elles le font de façon illégale et se servent comme moyen d'action de la violence.

Quant aux peuples autochtones, ils se voient reconnaître plus de droits que ceux reconnus aux minorités. La situation des Amérindiens et des Inuit au Canada est bien particulière. Là encore, malgré une absence de définition précise de «peuples autochtones», force est de constater que les Amérindiens et les Inuit forment des peuples. Il suffit pour nous en persuader de se référer à l'article 35 de la Loi constitutionnelle de 1982 qui les définit comme des

88. Pour eux, les Autochtones du Québec ne font pas partie de cette catégorie de peuples coloniaux qui auraient le droit de devenir indépendants par l'exercice du droit à l'autodétermination. 
peuples. La province de Québec a d'ailleurs reconnu les «nations autochtones» dans les quinze principes adoptés le 9 février 1983 par le conseil des ministres, ainsi que par la résolution de l'Assemblée nationale du 20 mars 1985. De plus, il a été demandé au gouvernement de faire des ententes avec les nations intéressées afin de leur accorder l'exercice «du droit à l'autonomie au sein du Québec [...] de façon à leur permettre de se développer en tant que nations distinctes ayant leur identité propre et exerçant leurs droits au sein du Québec». Le préambule de la Loi instituant la Commission sur l'avenir politique et constitutionnel du Québec ${ }^{89}$ accorde également des droits aux Amérindiens et aux Inuit. Il existe par ailleurs des instruments juridiques internationaux voulant protéger les droits des autochtones et particulièrement leurs droits de nature territoriale. Notons l'existence d'un Projet de Déclaration Universelle sur les droits des peuples autochtones ${ }^{90}$ qui leur octroie le droit à l'autodétermination (art. 3 et 31 ) et d'une Convention relative aux peuples indigènes et tribaux ${ }^{91}$ adoptée par l'Organisation Internationale du Travail en 1989 et entrée en vigueur en 1991, qui leur accorde le droit de disposer d'eux-mêmes seulement à l'intérieur de l'État.

Nous sommes d'avis que la coexistence de plusieurs peuples sur un même territoire n'est pas un obstacle à l'exercice de leur droit à l'autodétermination. L'emploi du terme «nation» pour désigner les autochtones traduit l'idée de race. Chaque peuple autochtone possède une langue, une culture et une histoire bien particulière, répondant ainsi au critère objectif nécessaire à la qualification de

89. L.Q., 1990, c. 34.

90. Sous-Commission de la lutte contre les mesures discriminatoires et la protection des minorités, Octobre 1991. Rapport du Groupe de travail sur les populations autochtones sur sa neuvième session, C.E.S., Doc. N.U. E/CN.4/Sub.2/1991/Rev.1, p. 53; Rapport du Groupe de travail sur les populations autochtones sur sa dixième session, C.E.S., Doc. N.U., E/CN.4/Sub.2/1992/33, p. 32. The Draft Declaration on the Rights of Indigenous Peoples, as approved by the members of the working Group on Indigenous Populations and Reported to the United Nations Sub-Commission on Prevention of discrimination and protection of minorities in August, 1993, [1994] 1 C.N.L.R. 40, and commentaries by D. SANDERS, p. 48 and by M.E. TURPEL, p. 50.

91. Convention $n^{\circ} 169$, n'a été ratifiée que par quelques États dont la Norvège, du Mexique, de la Colombie et de la Bolivie; voir également sur les autochtones : A. BISSONNETTE, «Le droit à l'autonomie gouvernementale des peuples autochtones : un phénix qui renaîtra de ses cendres», (1993) 24 R.G.D. 5; R.N. CLINTON, «The Rights of Indigenous Peoples as Collective Group Rights», (1990) 32 Arizona Law Review 739. 
peuples. Les événements de l'été 1990 démontrent de plus le désir des Mohawks de vivre ensemble, répondant cette fois au critère subjectif par leur volonté de vivre ensemble. Les caractéristiques communes à chacun des groupes autochtones et leur désir de vivre ensemble indique de façon indéniable que les autochtones forment des peuples. Notre analyse nous conduit à considérer les autochtones comme formant des peuples minoritaires, vu l'immigration massive de «l'homme blanc» ${ }^{92}$. Il existe actuellement 11 nations ou peuples autochtones au Québec, et à la lumière des Pactes internationaux relatifs aux droits de l'Homme plus particulièrement, chacune de ces nations pourrait devenir souveraine si elle possédait les éléments fondamentaux pour se constituer en État. Ces nations pourraient en outre décider de faire partie d'un Québec souverain, ou demeurer au sein du Canada si telle était leur volonté. Les Cris de la Baie James ont exprimé leur désir de vivre en tant que peuple; et ils sont un peuple vu leurs coutumes, leur droit, leur langue et leur économie qui leur sont particuliers. Leur dimension politique et internationale existe par la création d'une ambassade de la nation crie. Même si actuellement, ils ne revendiquent pas leur souveraineté, cette option demeure envisageable ${ }^{93}$. Ils ont par ailleurs affirmé vouloir tenir un référendum pour déterminer s'ils se rattacheraient au Canada, au Québec, ou se constitueraient en État advenant un référendum sur la séparation du Québec. Le Grand conseil des Cris a annoncé, le 19 février 1995 la formation de la Commission Eeyouch sur l'avenir, le statut et les droits des Cris de la Baie James en cas de souveraineté du Québec. La nation huronne-wendat a eu l'occasion de se prononcer quant à la position qu'elle adopterait si la province de Québec décidait de son avenir :

«Nous sommes prêts en tout temps à nous asseoir et à discuter avec le Québec, mais en aucun cas nous ne le ferons pour diminuer notre propre souveraineté ou nos droits...»

92. Voir également l'article rédigé par le Vice-Grand chef du Grand conseil des Cris du Québec: D.R. SAGANASH, «Le droit à l'autodétermination des peuples autochtones», (1993) 24 R.G.D. 85. V. C. TENNANT, «Indigenous Peoples, International Institutions, and the International Legal Literature from 1945-1993», (1994) 16 Human Rights Quarterly 1-57. E. STAMATOPOULOU, «Indigenous Peoples and the United Nations : Human Rights as a Developing Dynamic», (1994) 16 Human Rights Quarterly 58-81.

93. Status and rights of the James Bay Crees, supra, note 80, à la p. 45. 
Les peuples autochtones insistent particulièrement pour une reconnaissance d'un droit inhérent à l'autonomie gouvernementale.

Le fait pour les peuples autochtones de posséder leur propre gouvernement leur permettrait de ce fait de protéger les droits des autochtones, les droits et libertés de la personne possiblement menacés par les abus de gouvernements «étrangers». Le droit international a voulu permettre aux peuples d'exercer leur droit à l'autodétermination afin de réduire ainsi les tensions entre peuples. Chaque peuple aurait donc le droit de choisir son statut politique. La communauté internationale les a toujours incités à se libérer de forces opprimantes. Certains ont stipulé que le droit de se constituer en État était réservé aux peuples coloniaux dont le territoire était séparé de celui de la métropole par un espace maritime, afin que soit préservée l'intégrité territoriale. Or l'auteur R.L. Barsh réfute, à juste titre, cette théorie :

«It makes no sense historically or geographically to make the right to selfdetermination depend on a few miles of ocean. An invasion is an invasion; whether it is by land or by sea» ${ }^{94}$,

Il est intéressant de constater que de nombreux pays coloniaux et entités fédérées ayant accédé à l'indépendance, ont souvent invoqué le principe du respect de l'intégrité territoriale par les peuples minoritaires se situant sur leur territoire. De tels arguments ont été émis afin de protéger une unité nationale précaire. Le Québec serait bien mal venu d'invoquer la Déclaration sur les relations amicales ${ }^{95}$ de 1970 afin de maintenir l'unité territoriale, vu que luimême aurait rejeté son application afin de devenir souverain. Ce principe n'est ni déclaratoire d'une règle coutumière, ni l'assise du développement d'une telle règle. Ainsi, l'article 3 de l'Avant-projet de Loi sur la souveraineté du Québec fait en sorte que le Québec applique cette Déclaration en stipulant que la nouvelle constitution du Québec doit «reconnaître aux nations autochtones le droit de se gouverner sur des terres leur appartenant en propre. [...] cette reconnaissance s'exer[çant] dans le respect de l'intégrité du territoire québécois.» Cet article restreint les droits des autochtones en ce qu'il renferme dans

94. R.L. BARSH, «Indigenous Peoples and the Right to Self Determination», dans International Law and Aboriginal Human Rights, Sydney, The law book company Ltd, 1988, p. 72.

95. Supra, note 6 . 
Les frontières terrestres

(1994-95) 25 R.D.U.S. d'un Québec souverain à la lumière

du droit international contemporain

un même paragraphe et subordonne à une même condition soit le respect de l'intégrité du territoire québécois, les droits de la communauté anglophone et des nations autochtones. De plus, les autochtones ne sont pas qualifiés de peuples dans cet article. Ainsi, leur droit d'accéder à l'indépendance ne serait pas reconnu dans cette nouvelle constitution ${ }^{96}$.

Il est également possible de considérer, dans une certaine mesure, le droit pour un peuple de s'autodéterminer comme complémentaire du principe de l'intégrité territoriale. Le maintien de l'unité territoriale de l'État repose, en pratique, sur le comportement du gouvernement central. S'il accepte de respecter l'exercice du droit pour un peuple de s'autodéterminer au niveau interne, de lui accorder une plus grande autonomie au sein de l'État, ce peuple sera moins porté à demander l'indépendance. L'État doit tenir compte des évolutions qui se font sur son territoire et doit être à même de s'adapter aux changements nationaux découlant du droit pour un peuple de se constituer en État souverain. Il faut par ailleurs examiner si le contrôle exercé par l'autorité indépendantiste sur le territoire revendiqué et sur la population est effectif, pour lui permettre de devenir un État. «Le territoire d'un État n'est pas immuable» ${ }^{97}$. Par ailleurs, le faible nombre de personnes dont se compose un peuple n'est pas un obstacle à l'exercice du droit de sécession :

«State practice seems to indicate that no such minimum limit exists. Examples of States with very small populations include Tuvalu (pop. 8,229), Nauru (pop. 8,042), San Marino (pop.22,206), Liechtenstein (pop. 26,680), Andorra (pop. $42,000) .{ }^{98}$

96. C. HILLING, «Autodétermination et sécession confondues», Le Devoir, 13 janvier, 1995, p. A-9.

97. A. N'KOLOMBUA, «L'ambivalence des relations entre le droit des peuples à disposer d'eux-mêmes et l'intégrité territoriale des États en droit international contemporain», dans le Droit des peuples à disposer d'eux-mêmes, méthode d'analyse du droit international, Paris, Éditions A. Pedone, 1984, p. 434.

98. I. FSADNI, «Criteria for Statehood», dans Canadian Council on International Law, Bulletin, 1989, vol. 16, n $^{\circ} 3$, p. 8. 


\subsection{Contestation de l'application de la règle de l'uti possidetis au Québec}

Les peuples autochtones ${ }^{99}$ et notamment les Cris de la Baie James ${ }^{100}$ revendiquent l'exercice de leur droit à l'autodétermination sur leurs territoires traditionnels de 1898 et 1912 qui forment les deux tiers du territoire québécois. Ils ont retenu la thèse que les territoires octroyés au Québec en 1898 et 1912 le furent car le Québec faisait partie de la fédération canadienne et dans le but d'étendre le territoire. Le fait pour le Québec de devenir souverain lui retirerait l'acquis de ces territoires. Or, comme nous l'avons déjà mentionné ${ }^{101}$, cette théorie doit être écartée car elle aboutit à appliquer des règles de droit civil à une situation qui relève du droit constitutionnel.

Par ailleurs, les Cris de la Baie James rejettent l'application automatique au Québec souverain du principe de l'uti possidetis juris. D'après eux :

«The rule of uti possidetis would not automatically apply in the case of Quebec secession. Nor does it appear to be a universal principle that has had widespread application in non-colonial situations. Moreover, the appropriateness of applying such a rule in the context of Quebec secession and the competing aboriginal rights of self-determination must be seriously challenged. The reasons are as follows :

i) It is critical to note that the rule of uti possidetis is not a mandatory one under international law» ${ }^{102}$ (l'italique est de nous)

L'arrêt Burkina Faso ${ }^{103}$ a déjà exprimé, comme nous l'avons mentionné, que la règle de l'uti possidetis était d'application générale et donc applicable tant aux colonies devenant indépendantes qu'aux états sécessionnistes ${ }^{104}$, comme le

99. Journal des débats, Commission d'études des questions afférentes à l'accession du Québec à la souveraineté, Assemblée nationale, 1ère sess., 34e législature, 11 février 1992, n 27 , p. CEAS-816.

100. Status and rights of the James Bay Crees, supra, note 80, aux pp. 74 et ss.

101. Voir les commentaires émis relativement aux notes 80 et suivantes.

102. Status and rights of the James Bay Crees, supra, note 80, à la p. 79.

103. Supra, note 17.

104. Voir les commentaires émis relativement aux notes 33 et suivantes. 
démontre la récente accession des états à la souveraineté à travers le monde. $\mathrm{Ce}$ principe est devenu une règle coutumière, consolidée par la récente pratique des États nouvellement indépendants et par l'existence d'une opinio juris. Mais il est vrai que par consentement mutuel des parties intéressées celles-ci peuvent décider d'écarter son application.

Les peuples autochtones et les Cris invoquent ${ }^{105}$ :

«...in no case has the International Community recognized, as an institution of international law, the principle of uti possidetis. It remains, just like the Bull of Pope Alexander VI wherein it originates, derogatory to general international law, which insists on occupation as a basis for sovereignty. A rule derogating to generally accepted customary international law is binding only on those persons which have, by a Convention, expressly agreed to it.» ${ }^{106}$

Une entité doit, pour se constituer en État, posséder un contrôle effectif sur sa population permanente, son territoire délimité, et être indépendante dans ses relations extérieures. L'exercice d'un contrôle effectif et l'application de l'uti possidetis juris ne sont pas nécessairement incompatibles. En effet, afin de maintenir des relations de paix entre les parties concernées l'état accède à la souveraineté dans les limites qu'il possédait déjà, donc en principe sur le territoire soumis à son contrôle effectif. Le Québec possède-t-il un contrôle effectif sur le nord de son territoire? Le climat arctique, l'accès difficile et le faible nombre de personnes s'y trouvant relativisent ce qu'il faut entendre par contrôle effectif $^{107}$. Ce territoire est sous sa juridiction puisque les lois y sont appliquées, des Québécois y vivent, des infrastructures québécoises ont été mises en place afin d'assurer des services politiques, économiques et éducatifs; sont présents des barrages hydro-électriques et des villes minières.

De façon générale, le Québec possède un contrôle sur sa population et sur son territoire. Pousser davantage la signification de l'existence d'une occupa-

105. Status and rights of the James Bay Crees, supra, note 80, à la p. 80 .

106. Ibid., reprenant M.M. WHITEMAN, Digest of International Law, Department of State Publication, Washington, D.C., 1963, p. 1086.

107. Voir Affaire du Groenland oriental (Danemark c. Norvège), arrêt du 5 avril 1933, C.P.J.I., Recueil 1933, série A/B n 53, p. 2. 
tion effective peut conduire à prôner la violence contraire à la création même de ces principes. Par contre, nous sommes d'avis que sur certaines parcelles de territoire, la présence québécoise est pratiquement inexistante comparativement à la grande concentration de peuples autochtones s'y trouvant. Par conséquent, les nations autochtones pourraient à leur tour exercer leur droit à l'autodétermination sur ces parcelles de territoire et accéder à la souveraineté, se rattacher au Québec souverain ou demeurer au sein du Canada, si en plus de leur présence physique ils instauraient des infrastructures en ces endroits.

Poursuivant leur analyse, ces nations autochtones affirment que le principe de l'uti possidetis contrevient au droit à l'autodétermination des peuples, et que son application serait donc fonction de l'existence d'un consentement entre les parties concernées. Elles citent à cet effet l'affaire Burkina Faso ${ }^{108}$, qui affirme cependant que les problèmes de stabilité causés par un tel conflit de principes juridiques «a amené» les États africains à consentir au respect des frontières coloniales $^{109}$. Il n'y a donc pas d'obligation pour l'état voulant accéder à l'indépendance d'obtenir le consentement d'autres peuples qui exercent leur droit à l'autodétermination sur ce même territoire, mais cet état a tout intérêt à obtenir un tel accord afin d'exercer un contrôle effectif sur son territoire.

Enfin, d'après les Cris de la Baie James, la règle de l'uti possidetis est une exception qui doit être interprétée de façon restrictive. Nous avons de la difficulté à concevoir une telle interprétation puisqu'aucune restriction ne semble être applicable à cette règle; elle s'applique ou ne s'applique pas.

Par conséquent, une seule situation demeure problématique. Il s'agit de celle où le Québec réclame la souveraineté en même temps que les peuples autochtones exercent leur droit à l'autodétermination soit par une accession à la souveraineté, soit par un rattachement au reste du Canada. Nous sommes d'avis que le Québec devra redessiner ses frontières en fonction des régions délimitées et occupées par des peuples qui auront exercé leur droit à l'autodétermination de la façon décrite ci-dessus et qui exerceront un contrôle effectif sur leur territoire et leur population. Ainsi, par accord, le Québec devrait avec ses

108. Supra, note 17, à la p. 567.

109. Status and rights of the James Bay Crees, supra, note 80, à la p. 82. 
peuples négocier les frontières appropriées. Il est intéressant de voir la position de force dans laquelle seraient placés les peuples autochtones. En effet, les enjeux économiques pour le Québec, si des peuples autochtones décidaient d'exercer de façon externe leur droit à l'autodétermination, seraient considérables vu l'emplacement des barrages hydro-électriques de la baie James. Il semblerait qu' un contrôle effectif par des nations autochtones sur le territoire où se trouve le barrage autoriserait ces peuples en vertu du paragraphe 1a) de l'article 15 de la Convention de Vienne sur la succession d'États en matière de biens, archives et dettes d'États, qui codifie le droit coutumier, à exercer leur souveraineté sur cette partie du territoire. S'agissant d'une règle à laquelle on peut déroger par accord, les autochtones seraient en position de force dans les négociations. Mais encore faut-il qu'ils aient un contrôle effectif sur le territoire, or le Québec verrait sûrement à contrôler cette région. À défaut d'accord concernant les frontières, l'Assemblée générale des Nations Unies pourrait demander à la Cour Internationale de Justice ${ }^{110}$ de délimiter les frontières dans un avis consultatif. Dans la pratique, l'exercice du droit à l'autodétermination au niveau externe par des peuples différents se fait de façon successive et donc l'application de l'uti possidetis juris s'en trouve facilitée : chaque peuple accède à la souveraineté dans les limites définies du territoire qu'il contrôle.

\subsection{Le territoire des nations autochtones : territoire sur lequel ils ont un contrôle effectif}

En l'absence de limites administratives existantes, les peuples autochtones devraient créer des limites autour des régions sur lesquelles ils possèdent un contrôle effectif. Le contrôle doit être effectif sur leur population et leur territoire afin qu'ils puissent devenir souverains ou se rattacher au Canada. Il ne faut pas l'oublier, le contrôle que peut exercer un gouvernement sur sa population est avant tout basé sur les liens qui unissent la population et le territoire qu'elle occupe ${ }^{111}$. Il faut comprendre le lien spirituel qui unit les autochtones à leur terre :

110. Statut de la Cour Internationale de Justice, (1945) 15 C.N.U.C.I.O. 365, art. 34-36, 65 et ss.; voir R. SCHAFFER, «International Law and Sovereign Rights of Indigenous Peoples», dans International Law and Aboriginal Human Rights, Sydney, The law book company Ltd, 1988, p. 19-42.

111. R. SCHAFFER, ibid. 
«It must be understood that, for indigenous populations, land does not represent simply a possession or means of production. It is not a commodity that can be appropriated, but a physical element that must be enjoyed freely. It is also essential to understand the special and profoundly spiritual relationship of indigenous peoples with Mother Earth as basic to their existence and to all their beliefs, customs, traditions and culture.» ${ }^{12}$

D'ailleurs le mot autochtone signifie «né du sol lui-même» ${ }^{113}$. Est-ce à dire que les peuples autochtones auraient droit, comme certains le prétendent, aux territoires sur lesquels ils ont exercé leurs droits de pêche ou de chasse depuis la nuit des temps? Nous ne le pensons pas. Cette thèse extrémiste s'apparente à une appropriation injustifiée plutôt qu'à l'exercice légitime d'un droit de sécession ou de rattachement. Ce qui importe, nous avons déjà eu l'occasion de le mentionner, c'est «l'instantané territorial». Il faudra donc considérer leur territoire, leur population et leur contrôle au moment où ils voudront soit devenir indépendants soit se rattacher au Canada. Bien sûr, le territoire à considérer pourra correspondre à celui de leur réserve, ou être plus grand, car leur création visait à maintenir leurs traditions, à bénéficier d'un support collectif et à garder ainsi une certaine unité sans oublier le contrôle et l'espoir de les assimiler à la société nord-américaine, en leur offrant parfois une assiette territoriale minime.

Quant aux Cris et aux Inuit, ils ont renoncé à «leurs revendications, droits, titres et intérêts autochtones, quels qu'ils soient, aux terres et dans les terres du territoire et du Québec...». Le Québec et le Canada ont consenti à cette cession. En revanche, ils ont acquis certains droits et avantages : ils possèdent la propriété des terres tombant dans la catégorie I, ont des droits exclusifs de chasse, de pêche et de trappage sur les terres de la catégorie II, quant aux terres de la catégorie III, ils ont des droits privilégiés, droit d'accès et d'utilisation qui ne leur sont pas exclusifs.

«Pour étendus qu'ils soient, ces droits s'analysent, au maximum, comme des droits de propriété (catégorie I) ou d'usage (catégories II et III). Et il n'est pas

112. Ibid.

113. E. GOURDEAU, «La question autochtone», reproduit dans Recueil des exposés et études soumis à la Commission d'étude des questions afférentes à l'accession du Québec à la souveraineté, volume 1, tome 1, 1992, à la p. 255. 
Les frontières terrestres
(1994-95) 25 R.D.U.S. $\quad$ d'un Québec souverain à la lumière
du droit international contemporain

indifférent de constater que, même en ce qui concerne les terres relevant de la catégorie $\mathrm{I}$, le Québec conserve le droit de les utiliser «à des fins publiques», la propriété des droits miniers et souterrains (même si les populations autochtones doivent consentir aux exploitations minières) et «certains pouvoirs d'expropriation.» ${ }^{114}$

Les Cris revendiquent les territoires de 1898 et 1912 comme étant leurs territoires traditionnels. Or, ces mêmes territoires furent occupés par d'autres peuples dont les Inuit, pendant des centaines d'années. Nous suggérons comme limites de leur territoire les terres de la catégorie I et II, sous contrôle effectif des Cris et Inuit. Ces limites sont néanmoins fonction de la situation et peuvent faire l'objet de négociations si cela s'avère nécessaire. Par ailleurs, rien n'empêche la création d'une fédération autochtone, si telle était la volonté des peuples. Si les peuples désireux de devenir souverains ou de se rattacher au Canada n' arrivaient pas à définir leurs limites territoriales, l'Assemblée générale des Nations Unies pourrait saisir la Cour Internationale de Justice afin qu'elle émette un avis consultatif délimitant leurs territoires, car seuls des États peuvent être jugés devant cette cour.

Même si le choix revient en définitive aux autochtones sur les modalités d'exercice du droit à disposer d'eux-mêmes, nous pensons en l'absence d'assiette territoriale définie et vu la perte d'une partie de leurs caractéristiques ancestrales, qu'il serait plus avantageux pour les autochtones de demeurer à l'intérieur d'un État. D'autre part, si le fait d'accéder à l'indépendance leur permettait de retrouver pleinement leurs coutumes, un tel État pourrait difficilement s'adapter à une communauté formée d'États «modernes» :

«Quoi qu'il en soit, il faut espérer que la fin du 20ième siècle marquera également la fin d'un régime qui garde sous tutelle directe ou indirecte les Amérindiens, les réduit à un statut de citoyens mineurs et perpétue leur état de dépendance; un état qui leur nie en quelque sorte la fierté qui caractérisait leurs ancêtres et qui leur avait valu - lors des conquêtes française et anglaise - d'être à la fois craints et respectés.» ${ }^{115}$

114. T.M. FRANCK, loc. cit., supra, note 9, à la p. 393.

115. E. GOURDEAU, loc. cit., supra, note 113, à la p. 268. 
En vertu des règles du droit international relatives au droit des traités et à la succession d'États en matière de traités, le Québec souverain conserverait son unique frontière internationale qu'il avait en tant que province. Ainsi, la frontière Québec/États-Unis demeurerait à moins d'accord contraire de la part des deux parties. D'autre part notre analyse nous conduit à conclure à l'application de l'uti possidetis juris et donc à l'attribution à un Québec souverain des frontières délimitant son territoire provincial. Cette thèse n'est valable qu'en l'absence de tout exercice du droit de sécession ou de tout rattachement au Canada par les nations autochtones. Toutefois, face à une telle volonté de la part des nations autochtones, le Québec se verrait amputer de régions territoriales alors sous leur contrôle effectif. L'implosion du Canada serait donc à l'origine de la naissance de plusieurs pays ou d'un nouveau tracé des frontières du Québec, dans l'hypothèse où des nations autochtones voudraient se rattacher au Canada. Ainsi, seul l'exercice du droit à l'autodétermination sous l'angle décrit ci-dessus par les nations autochtones pourrait être à l'origine d'une nouvelle morphologie des frontières du Québec, attendu que les minorités à l'intérieur du Québec ne disposent pas du droit à l'autodétermination.

Si le Québec accède au statut d'État souverain, ses nouvelles frontières bénéficieront de la protection du droit international, qui se porte garant du respect de la stabilité des frontières devenues internationales. En effet, l'État québécois serait notamment protégé par la Charte des Nations Unies ${ }^{116}$ et son article 2 qui stipule :

«L'Organisation des Nations Unies et ses Membres, dans la poursuite des Buts énoncés à l'article 1, doivent agir conformément aux Principes suivants : [...]

4. Les Membres de l'Organisation s'abstiennent, dans leurs relations internationales, de recourir à la menace ou à l'emploi de la force, soit contre l'intégrité territoriale ou l'indépendance politique de tout État, soit de toute autre manière incompatible avec les Buts des Nations Unies.» 
Cet article est renforcé par le préambule et les principes énoncés dans la Déclaration sur les relations amicales qui reprend entre autres l'article 2 de la Charte des Nations Unies et l'approfondit :

«Tout État a le devoir de s'abstenir de recourir à la menace ou à l'emploi de la force pour violer les frontières internationales existantes d'un autre État ou comme moyen de règlement des différends internationaux, y compris les différends territoriaux et les questions relatives aux frontières des États.»

Si la question de l'intégralité territoriale du Québec demeure importante, il ne faut pas envisager cette question sans prendre en considération le contexte politique et international dans lequel elle s'inscrit. En effet, l'heure est aux regroupements et à la création d'entités supranationales. La volonté de faire disparaître les obstacles à la libre circulation des personnes, des marchandises et des services transcende la notion d'identité nationale. Le nouvel ordre mondial se manifeste à la fois par la multiplication des nouveaux États sur la scène internationale et la création de regroupements politiques et économiques. Par conséquent, si le territoire physique d'un Québec souverain reste limité aux frontières actuelles de l'état fédéré québécois, le Québec conserve la possibilité d'élargir son territoire économique, voire même politique, à un ensemble relativement large de pays.

Un Québec souverain aura la possibilité d'élargir son espace économique et politique en devenant membre des organisations internationales à vocation économique. Il devra également essayer de s'intégrer dans un réseau de relations économiques internationales, en adhérant entre autres à l'accord de libre échange canado-américain et à l'A.L.E.N.A (Accord de Libre Échange Nord Américain) auquel adhère le Mexique. Mais un Québec souverain pourrait également imaginer la création d'une Union douanière (Québec-Canada), d'un marché commun ou d'une union économique et monétaire avec le Canada, voire même avec les États-Unis ${ }^{117}$. Il s'agira de mettre en place des régimes qui permettront le maintien de l'espace économique canado-québécois susceptible

117. Une option récemment envisagée a été la création d'une union monétaire Québec/États-Unis. Voir M. MASSE, «Une union monétaire avec les États-Unis permettrait d'éviter les principaux problèmes que cause l'association avec le Canada», Le Devoir, 12 mars, 1993, p. A-9. 
d'engendrer la libre circulation des personnes, des marchandises, des services et des capitaux. L'adhésion du Québec souverain au G.A.T.T., au F.M.I., à la Banque mondiale et à l'O.C.D.E. favorisera également l'insertion de cet État dans un espace économique mondial dont les frontières sont de moins en moins étanches.

Tout en étant maître de son avenir, un Québec souverain pourra ainsi repousser ses frontières et participer, comme les autres États, à l'édification d'une communauté internationale à laquelle il sera fier d'appartenir. 